\title{
Mineral Trioxide Aggregate Applications in Endodontics: A Review
}

\author{
Gabriele Cervino ${ }^{1, \odot ~ L u i g i ~ L a i n o ~}{ }^{2,1}$ Cesare D’Amico ${ }^{1}$ Diana Russo ${ }^{2}$ Ludovica Nucci ${ }^{2}$ Giulia Amoroso ${ }^{1}$ \\ Francesca Gorassini ${ }^{1}$ Michele Tepedino ${ }^{3}$ Antonella Terranova ${ }^{1}$ Dario Gambino ${ }^{1}$ \\ Roberta Mastroieni ${ }^{1}$ Melek Didem Tözüm ${ }^{4}$ Luca Fiorillo ${ }^{1}$
}

1Department of Biomedical, Dental, Morphological and
Functional Imaging Sciences, University of Messina,
Policlinico G. Martino, Messina, Italy
2Multidisciplinary Department of Medical-Surgical and
Dental Specialties, Second University of Naples, Naples, Italy
3Fondazione Policlinico Universitario A. Gemelli IRCCS,
Istituto di Clinica Odontoiatrica e Chirurgia Maxillo-Facciale,
Roma-Università Cattolica del Sacro Cuore, Rome, Italy
4Pre-Doctoral Clinics, College of Dentistry, University of Illinois
at Chicago, Chicago, Illinois, United States

Eur J Dent:2020;14:683-691

\begin{abstract}
Keywords

- dental materials

- Portland cements

- dentin

- pulp exposure

- pulp capping

- root canal filling

A current topic in dentistry concerns the biocompatibility of the materials, and in particular, conservative dentistry and endodontics ones. The mineral trioxide aggregate (MTA) is a dental material with biocompatibility properties to oral and dental tissues. MTA was developed for dental root repair in endodontic treatment and it is formulated from commercial Portland cement, combined with bismuth oxide powder for radiopacity. MTA is used for creating apical plugs during apexification, repairing root perforations during root canal therapy, treating internal root resorption, and pulp capping. The objective of this article is to investigate MTA features from a clinical point of view, even compared with other biomaterials. All the clinical data regarding this dental material will be evaluated in this review article. Data obtained from the analysis of the past 10 years' literature highlighted 19 articles in which the MTA clinical aspects could be recorded. The results obtained in this article are an important step to demonstrate the safety and predictability of oral rehabilitations with these biomaterials and to promote a line to improve their properties in the future.
\end{abstract}

\author{
Address for correspondence Luca Fiorillo, DDS, PhD, Department \\ of Biomedical, Dental, Morphological and Functional Imaging \\ Sciences, University of Messina, Policlinico G. Martino, \\ Via Consolare Valeria 1, 98100 Messina, Italy \\ (e-mail: Ifiorillo@unime.it).
}

\section{Introduction}

The mineral trioxide aggregate (MTA) is a hydrophilic and biocompatible endodontic cement, capable of stimulating healing and osteogenesis. It consists of a powder of fine trioxides (tricalcium oxide, silicon oxide, bismuth oxide) and other hydrophilic particles (tricalcium silicate, tricalcium aluminate, responsible for the chemical and physical properties of this aggregate), which hardens in the presence of humidity. ${ }^{1-5}$ The hydration of the powder results in the formation of a colloidal gel with $\mathrm{pH}$ 12.5 , which solidifies in a structure in about 3 to 4 hours. ${ }^{6-9}$
In the past 10 years, the MTA found its application in the field of dentistry with specific fit within the conservative and endodontic treatments. A dental trauma is an event that cannot be predicted and usually it is not easy for the clinicians to manage it. The dentist should therefore be prepared to intervene in patient who has suffered a dental trauma. Early intervention is often crucial to improve the prognosis of the trauma itself. In the presence of a coronal fracture with dentine exposure, the primary objective should be to seal dentinal tubules. Especially in a young patient, the size and 
number of dentinal tubules are large: even a small amount of exposed dentin therefore allows a large number of plaque bacteria and their metabolites to move to the underlying pulp and cause inflammation. An occurrence of this type could, sometimes in short time, lead to necrosis. When the dental trauma has caused a pulp exposure, the emergency intervention consists with the management of the exposed pulp. One of the treatments, besides the endodontic treatment, is direct capping or partial pulpotomy. Partial pulpotomy could be performed using MTA. The MTA could be applied as cement for its high compatibility, which has a mechanism similar to calcium hydroxide $\left(\mathrm{Ca}(\mathrm{OH})_{2}\right)$ (extremely basic) and therefore a powerful antibacterial.

Unlike $\mathrm{Ca}(\mathrm{OH})_{2}$, however, the MTA hardens, reaching a good consistency; it is, therefore, extremely suitable for any restoration. Fast hardening therefore allows partial pulpotomies performed with MTA to be restored in a definitive manner. $^{7}$

Pulp consisting of a cellular component, vessels and nerves; this tissue is called mature mucosal connective tissue. Endodontic therapy is used if a tooth carious or traumatic injury has caused an irreversible alteration of the pulp tissue and its necrosis. It is also possible to use this method if the dental element is to be involved in prosthetic rehabilitations, which due to the considerable reduction of the dental tissue, it would determine, with high probability, an irreversible pulp alteration. During endodontic treatment, blood contamination should be absolutely avoided, and the roots canal system needs to be dry, to obtain a successful root canal filling. During direct pulp capping or perforation sealing, it is fundamental to control the bleeding and obtain a dry field too. The mechanism of action of the MTA is related with the clinical features of the human oral cavity. MTA, when placed in direct contact with human tissues, is able to release calcium ions for cell proliferation. Moreover, it creates an antibacterial environment by its alkaline $\mathrm{pH}$, regulating the cytokine production. Therefore, it favors the migration and differentiation of hard tissue producing cells forming hydroxyapatite on MTA surface and providing a biological seal. Finally, during a surgical endodontic procedure, the retrograde cavity should be completely dry. This cement differs from all other materials currently in existence, thanks to its biocompatibility, its antibacterial properties, its marginal adaptation, and its sealing capacities, and finally, thanks to its hydrophilic nature. It is important to understand the functioning of this biomaterial, its behavior with contact with other materials used in dentistry, and above all, over time or from a clinical and radiographic point of view. ${ }^{10-12}$ Investigating these topics requires a research into the international literature, which also includes the use of cutting-edge technologies for examination. ${ }^{13-16}$

The purpose of this review is to evaluate all the recent scientific literature concerning this topic and to evaluate all its clinical features. The evaluation of different studies offers information about the facets of the material related to endodontics, conservative dentistry, and oral surgery.

\section{Materials and Methods}

\section{Protocol and Registration}

This article has been registered as review in a systemic review database called PROSPERO. It is an International Prospective Register of Systematic Reviews about health and social care. Obtained PROSPERO registration number is 156248 on October 27, 2019. The main question of this study has been elaborated following PICOT (Population/Intervention/ Comparison/Outcome/Time) study design.

This review follows a protocol according to PROSPERO and Preferred Reporting Items for Systematic Reviews and MetaAnalyses (PRISMA) (Transparent Reporting of Systematic Reviews and Meta-Analyses).

\section{Eligibility Criteria}

The results obtained from the literature search were filtered, through software and manual screening, according to the following inclusion and exclusion criteria:

- Inclusion criteria

- Human studies

- Information about MTA clinical use

- Information about MTA and other biomaterials in endodontics

- In vitro and in vivo studies about MTA

- Last 10 years of studies

\section{- Exclusion criteria}

- In silica studies

- Not on human studies

- Not in English

- Not accessible title or abstract

- Not enough information about main question

\section{Information Sources}

Results were obtained after a research and a screening on scientific international database as PubMed, Embase, and Web of Science. Automatic filter and platforms software have been used for results screening.

\section{Search}

Search has been conducted using this keyword on information sources: "Mineral Trioxide Aggregate." Search date is August 1, 2019.

The database search protocol details are: ("mineral trioxide aggregate" [Supplementary Concept] OR "mineral trioxide aggregate" [All Fields]) AND ("2009/10/30" [PDat]: “2019/10/27" [PDat] AND "humans" [MeSH Terms]).

Keywords have been chosen by authors after a discussion with the aim to include as large as possible number of results

(-Fig. 1).

PICO questions are:

- In dental patients, what is the effect of MTA use on pulp vitality?

- How MTA features could improve clinical success on dental patients? 


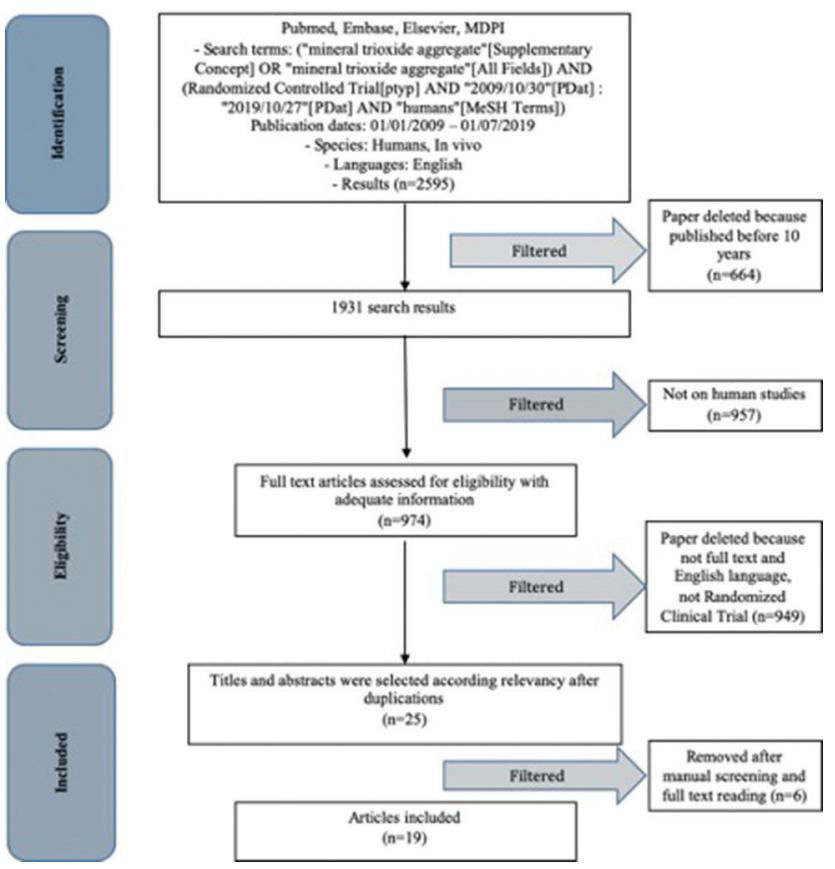

Fig. 1 Preferred reporting items for systematic reviews and meta-analyses flow chart.

\section{Study Selection}

Authors with the aim to include relevant studies for this review have conducted selection process. After applying the electronic eligibility criteria, the authors conducted a manual study selection independently.

\section{Data Collection Process}

Two independent authors from two different universities conducted the data collection process (D.R., University of Naples and L.F., University of Messina). After data screening completion, they clarified any doubt with other expert reviewers (M.D.T. and L.L.).

\section{Data Items}

The following data items were considered during data collection; summary measures and data items are shown in - Tables 1 and 2:

- Investigated data items on articles (-Table 2)

- Authors and year-article authors and year of publication (references have been added)w

- Sample-sample size and groups size

- Outcome-main results of the study

- Type of study-type of article.

Table 1 All mineral trioxide aggregate use

\begin{tabular}{|l|l|}
\hline \multirow{2}{*}{ Conservative dentistry } & Indirect pulp capping \\
\cline { 2 - 2 } & Direct pulp capping \\
\hline Endodontic dentistry & Root filling \\
\cline { 2 - 2 } & $\begin{array}{l}\text { Root filling with postcore } \\
\text { indication }\end{array}$ \\
\hline
\end{tabular}

\section{Summary Measures}

Summary measures are shown in $\boldsymbol{\bullet}$ Table $\mathbf{1}$.

\section{Synthesis of Results}

The authors performed the summary of the results manually, after reading the title, abstract, and full text of each article.

\section{Risk of Bias}

A risk of bias evaluation was performed according to Higgins et al. Risk of bias has been conducted to improve review quality according to PRISMA statement too. ${ }^{17-20}$

\section{Results}

\section{Study Selection}

The results were obtained in relation to the "Materials and Methods" instructions. Using the set out in paragraph 2.4 keywords, 2,595 results were obtained. Subsequently, according to eligibility criteria, results have been screened. The authors decided to maintain only past 10 years results to underline the novelty and accuracy on diagnostics method as well as the quality of the new technologies results in the field of MTA application. A total of 1,931 results remained after this first screening. Only 25 studies on human have been considered, and the authors analyzed full text and English articles. The last step to complete the revision of the results was to compare only review articles type. Only 19 results, after a reading and a manual authors screening, were resulted eligible for this study ( - Fig. 1).

\section{Results of Individual Studies}

Results of individual studies are listed in -Table 2 and - Fig. 2. The results are divided accordingly to PRISMA statement and organized into sample, items, outcomes, and type of study. Authors' name and year have been restricted following the interval time range of 10 years.

\section{Synthesis of Results}

Çelik et $\mathrm{al}^{20}$ analyzed differences between two groups of patients involved in pulpotomy treatment. The MTA groups had a $100 \%$ success rate at 24 months instead of $89.4 \%$ with Biodentine use. According to Erfanparast et $\mathrm{al}^{21}{ }^{21}$ there are no significant differences on resin-modified Portland cementbased materials versus MTA in direct pulp capping. After 12 months, the success rate for MTA and resin-modified one were 94.5 and $91.8 \%$, respectively. Koc Vural et al ${ }^{22}$ evaluated differences between $\mathrm{Ca}(\mathrm{OH})_{2}$ and MTA. The follow-up term for a total of 100 samples was of 24 months. Four $\mathrm{Ca}(\mathrm{OH})_{2}$ capped teeth and two MTA capped received endodontic emergency treatments. But there are no significant differences between groups. Kang et $\mathrm{a}^{23}$ studied clinical differences between three MTA groups (ProRoot MTA, Ortho MTA, and RetroMTA). The success rate at 1 year was high with no significant differences; the success rates were 96, 92.8, and $96 \%$, respectively (as listed in parentheses). Bakhtiar et $\mathrm{al}^{24}$ investigated differences on third molar pulpotomy between 
Table 2 Main results and item investigated on reviews

\begin{tabular}{|c|c|c|c|c|}
\hline Authors (y) & Sample & Items & Outcomes & Type of study \\
\hline Çelik et al $(2019)^{20}$ & $24+20$ & MTA vs. Biodentine & $\begin{array}{l}\text { Differences on success, } \\
p=0.646\end{array}$ & RCT \\
\hline $\begin{array}{l}\text { Erfanparast et al } \\
(2018)^{21}\end{array}$ & $46 \times 2$ (split mouth) & $\begin{array}{l}\text { Resin modified Portland } \\
\text { cement vs. MTA }\end{array}$ & $\begin{array}{l}\text { Differences are not signifi- } \\
\text { cant, } p>0.05\end{array}$ & RCT \\
\hline $\begin{array}{l}\text { Koc Vural et al } \\
(2017)^{22}\end{array}$ & $49+51$ & MTA vs. calcium hydroxide & $\begin{array}{l}\text { There are no differences } \\
\text { between used materi- } \\
\text { als, } p=0.238 \text { (or higher) }\end{array}$ & RCT \\
\hline Kang et al $(2017)^{23}$ & $33+36+35$ & $\begin{array}{l}\text { ProRoot MTA vs. Ortho MTA } \\
\text { vs. RetroMTA }\end{array}$ & $\begin{array}{l}\text { No significant differences } \\
\text { between groups }\end{array}$ & $\mathrm{RCT}$ \\
\hline $\begin{array}{l}\text { Bakhtiar et al } \\
(2017)^{24}\end{array}$ & $9+9+9$ & $\begin{array}{l}\text { TheraCal vs. Biodentine vs. } \\
\text { ProRoot MTA }\end{array}$ & $\begin{array}{l}\text { Normal pulp organization } \\
(p=0.06) \text {; dentinal bridge } \\
\text { formation }(p=0.001)\end{array}$ & $\mathrm{RCT}$ \\
\hline $\begin{array}{l}\text { Asl Aminabadi et al } \\
(2016)^{25}\end{array}$ & $40+40+40+40$ & $\begin{array}{l}\text { Simvastatin vs. } 3 \text { Mix vs. } \\
\text { 3Mixtatin vs. MTA }\end{array}$ & $\begin{array}{l}\text { No differences between } \\
\text { MTA and 3Mixtatin } \\
(p>0.05)\end{array}$ & RCT \\
\hline $\begin{array}{l}\text { Aminabadi et al } \\
(2016)^{26}\end{array}$ & $40+40$ & 3Mixtatin vs. MTA & $\begin{array}{l}\text { Clinical differences } \\
\text { between groups }\end{array}$ & $\mathrm{RCT}$ \\
\hline $\begin{array}{l}\text { Nowicka et al } \\
(2015)^{27}\end{array}$ & $11+11+11+11$ & $\begin{array}{l}\text { Calcium hydroxide, MTA, } \\
\text { Biodentine, Single Bond } \\
\text { Universal }\end{array}$ & $\begin{array}{l}\text { Reparative formed dentin } \\
\text { was less in Single Bond } \\
\text { Universal group; the mean } \\
\text { density of dentin bridges } \\
\text { was the highest in the MTA } \\
\text { group and the lowest in } \\
\text { the Single Bond Universal } \\
\text { group }\end{array}$ & $\mathrm{RCT}$ \\
\hline Kang et al $(2015)^{28}$ & $49+47+47$ & $\begin{array}{l}\text { RetroMTA vs. Ortho MTA vs. } \\
\text { PRoRoot MTA }\end{array}$ & $\begin{array}{l}\text { Clinical success rate is } \\
\text { similar and not statistically } \\
\text { significant }\end{array}$ & $\mathrm{RCT}$ \\
\hline $\begin{array}{l}\text { Bonte et al } \\
(2015)^{29}\end{array}$ & $15+15$ & MTA vs. calcium hydroxide & $\begin{array}{l}\text { Success rate demonstrated } \\
\text { a difference between } \\
\text { groups, } p<0.7\end{array}$ & RCT \\
\hline $\begin{array}{l}\text { Petrou et al } \\
(2014)^{30}\end{array}$ & $31+26+29$ & $\begin{array}{l}\text { Calcium hydroxide vs. medi- } \\
\text { cal Portland cement vs. white } \\
\text { MTA }\end{array}$ & $\begin{array}{l}\text { Difference between } \\
\text { groups are not significant } \\
(p=0.72)\end{array}$ & RCT \\
\hline $\begin{array}{l}\text { Hilton et al } \\
(2013)^{31}\end{array}$ & $181+195$ & Calcium hydroxide vs. MTA & $\begin{array}{l}\text { Failure rate at } 24 \text { mo was } \\
31.5 \% \text { for calcium hydrox- } \\
\text { ide and } 19.7 \% \text { for MTA }\end{array}$ & RCT \\
\hline $\begin{array}{l}\text { Gandolfi et al } \\
(2013)^{32}\end{array}$ & $8+8$ & AH Plus vs. MTA Flow & $\begin{array}{l}\text { MTA flow sealer created a } \\
\text { dense apatite layer after } \\
7 \mathrm{~d}\end{array}$ & $\mathrm{RCT}$ \\
\hline $\begin{array}{l}\text { Bernabé et al } \\
(2013)^{33}\end{array}$ & 34 & ProRoot MTA & $\begin{array}{l}\text { Sonic vibration could be } \\
\text { considered an efficient aid } \\
\text { to improve MTA sealing } \\
\text { ability }\end{array}$ & RCT \\
\hline $\begin{array}{l}\text { Sönmez et al } \\
(2012)^{34}\end{array}$ & $15+15+15+6$ & $\begin{array}{l}\text { AH Plus vs. MTA Fillapex vs. } \\
\text { ProRoot MTA vs. control }\end{array}$ & $\begin{array}{l}\text { MTA Fillapex had higher } \\
\text { microleakage values, } \\
p<0.05\end{array}$ & $\mathrm{RCT}$ \\
\hline $\begin{array}{l}\text { Leye Benoist et al } \\
(2012)^{35}\end{array}$ & 60 & MTA vs. calcium hydroxide & $\begin{array}{l}\text { Success rates are different } \\
\text { between groups at } 3 \mathrm{mo} \text {, } \\
p=0.02\end{array}$ & $\mathrm{RCT}$ \\
\hline $\begin{array}{l}\text { Ghoddusi et al } \\
(2012)^{36}\end{array}$ & & MTA vs. ZOE) & $\begin{array}{l}\text { MTA and ZOE showed both } \\
\text { clinical success }\end{array}$ & RCT \\
\hline $\begin{array}{l}\text { Hansen et al } \\
(2011)^{37}\end{array}$ & $12+12$ & $\begin{array}{l}\text { ProRoot MTA vs. } \\
\text { EndoSequence Root Repair } \\
\text { Material }\end{array}$ & $\begin{array}{l}\text { pH level was } \\
\text { higher for MTA and } \\
\text { EndoSequence } p<0.05\end{array}$ & $\mathrm{RCT}$ \\
\hline $\begin{array}{l}\text { Yildirim et al } \\
(2009)^{38}\end{array}$ & $15+15+15+6$ & $\begin{array}{l}\text { Gutta-percha vs. Gutta- } \\
\text { percha prepared with gates } \\
\text { vs. MTA vs. control }\end{array}$ & $\begin{array}{l}\text { MTA showed less microle- } \\
\text { akage, } p<0.005\end{array}$ & $\mathrm{RCT}$ \\
\hline
\end{tabular}

Abbreviations: MTA, mineral trioxide aggregate; RCT, randomized controlled trial; ZOE, zinc oxide eugenol. 


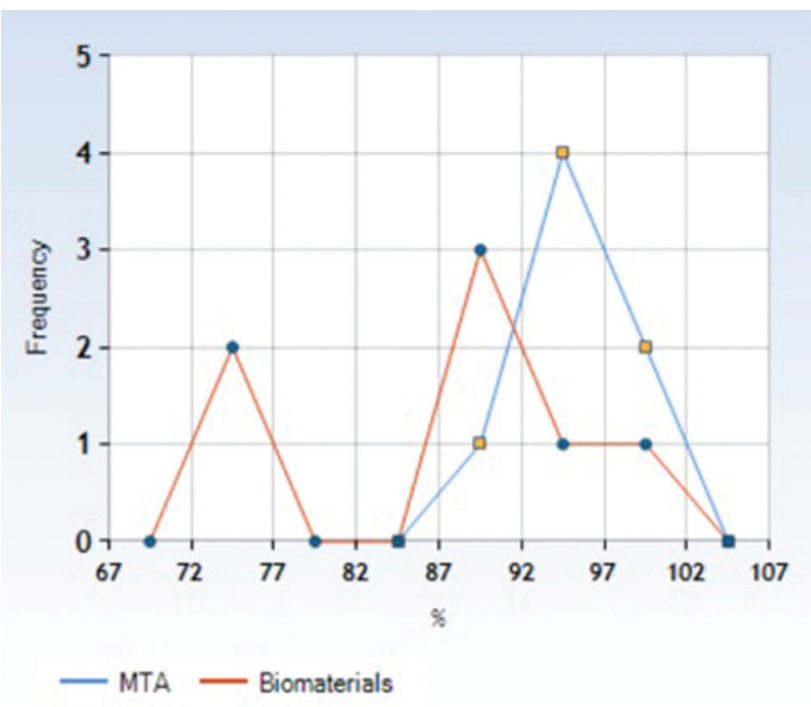

Fig. 2 Success rate frequency polygon chart of MTA (blue) versus other biomaterials. MTA, mineral trioxide aggregate.

three different materials (TheraCal, Biodentine, and ProRoot). They showed how there were no clinical signs on ProRoot MTA and Biodentine groups as two patients reported significant pain in TheraCal group. Pulp reorganization was seen in $33.33 \%$ of ProRoot MTA, $11.11 \%$ of TheraCal, and $66.67 \%$ of Biodentine groups. Moreover, dentinal bridge formation was seen on $11 \%$ of TheraCal and $56 \%$ of ProRoot MTA. Asl Aminabadi et $\mathrm{al}^{25}$ tested clinical differences between four groups for direct pulp capping. Noncaries pulpal exposures were treated with simvastatin, 3Mix, 3Mixtatin, or MTA. At the end of a 12-month follow-up period, the overall success rates were 93.8\% (MTA), 91.9\% (3Mixtatin), 62.5\% (3Mix), and $57.1 \%$ (simvastatin). According to the authors, there were no significant differences $(p=0.05$ ) between MTA and 3Mixtatin groups. 3Mixtatin groups had a statistical difference on simvastatin and 3Mix groups $(p<0.01)$. Another study of Aminabadi et $\mathrm{al}^{26}$ confirmed 3Mixtatin efficiency on pulp capping. The authors inspected MTA versus 3Mixtatin on direct pulp capping with a $96.8 \%$ of success rate against MTA with $48.6 \%$ of referred pain. Nowicka et al ${ }^{27}$ evaluated differences on direct pulp capping between four groups: $\mathrm{Ca}(\mathrm{OH})_{2}$, MTA, Biodentine, and Single Bond Universal. The reparative dentin formed in the $\mathrm{Ca}(\mathrm{OH})_{2}$, MTA, and Biodentine was superior to the Single Bond Universal group. Moreover, the dentin bridges density was the highest in the MTA group and the lowest in the Single Bond Universal group. Kang et al ${ }^{28}$ published a report about differences on three MTA materials. At 12 months, the radiographic success rates in these groups were 100\% (RetroMTA), $97.4 \%$ (Ortho MTA), and 100\% (ProRoot MTA). The Kaplan-Meier's survival function relative to clinical and radiographic rates did not differ between groups. According to Bonte et al, ${ }^{29}$ MTA at 12 months produced mineralized barrier in $82.4 \%$ of cases instead of $\mathrm{Ca}$ $(\mathrm{OH})_{2}(50 \%)$. Pain and tenderness to percussion had disappeared in both groups. In a Petrou et a ${ }^{30}$ randomized controlled trial, it was demonstrated at 6.3 months of time on 86 patients how $\mathrm{Ca}(\mathrm{OH})_{2}$ versus medical Portland cement versus white MTA did not show any statistical difference. The total success rate was $90.3 \%$. Hilton et al ${ }^{31}$ recently published a study about the clinical and radiographic differences on two direct capping materials groups, $\mathrm{Ca}(\mathrm{OH})_{2}$ versus MTA. MTA showed a less failure rate $(p=0.046)$. Gandolfi et $\mathrm{al}^{32}$ analyzed, through a three-dimensional microcomputed tomography (3D micro-CT) analysis, differences between AH Plus and MTA flow on their microstructure. Bernabé et $\mathrm{al}^{33}$ tested the MTA sealing ability for apicectomy. They filled with MTA plus sonic, ultrasonic, or no vibration. The sonic vibration could improve sealing level. Sönmez et $\mathrm{al}^{34}$ showed differences on the apical microleakage between AH Plus, MTA Fillapex, and ProRoot MTA. Fillapex had better results about microleakage and there are no statistical differences between AH Plus and MTA. Leye Benoist et a ${ }^{35}$ highlighted differences between $\mathrm{Ca}(\mathrm{OH})_{2}$ and MTA for indirect pulp capping. At 3 months, the success rate of MTA was $93 \%$ instead of $73 \%$ for $\mathrm{Ca}(\mathrm{OH})_{2}$. At 6 months, the success rate was $89.6 \%$ for MTA instead of $73 \%$. The mean initial residual dentine thickness was $0.23 \mathrm{~mm}$, this value has been increased to $0.121 \mathrm{~mm}$ with MTA and 0.136 with $\mathrm{Ca}(\mathrm{OH})_{2}$ at 3-month time. According to Ghoddusi et al, ${ }^{36}$ there are no statistical differences between MTA or zinc oxide eugenol (ZOE) in pulpotomy after a carious or traumatic pulp exposure. Hansen et $\mathrm{al}^{37}$ considered the $\mathrm{pH}$ level with the use of different biomaterials for pulp capping. The authors studied MTA, Endodontic Sealing(ES); control pairs were filled with $\mathrm{Ca}(\mathrm{OH})_{2}$ (positive group) and saline (negative). The $\mathrm{pH}$ was measured at 20 minutes, 3 hours, 24 hours, and 1-2 to 3-4 weeks. The MTA pH was significantly higher during the time than ES (at 1 week, $p<0.0001$ ). Yildirim et al ${ }^{38}$ discovered differences on filling between gutta-percha with two methods and MTA. Cervino et al obtained better results with MTA, then showed less microleakage ( - Fig. 3). ${ }^{7}$

\section{Discussion}

All the conclusions of the selected articles for this present review have been summarized in this section as follows: Çelik et $\mathrm{al}^{20}$ evaluated clinical success differences between MTA and Biodentine. The authors showed how both MTA and Biodentine are appropriate options for pulpotomy. According to this study, it seems how the etiology of pulp exposure is the crucial on pulpal response (mechanical or carious) whether or not the kind of material applied. Erfanparast et $\mathrm{al}^{21}$ concluded that resin-based Portland cement results are comparable to MTA for primary molars after 12 months of follow-up and no significant differences can be underlined between the two biomaterials investigated. Koc Vural et al performed a similar study, about the comparison of two endodontic materials. ${ }^{22}$ The authors reported that $\mathrm{Ca}(\mathrm{OH})_{2}$ and MTA are both accepting pulp-capping materials at a 24-month follow-up term.

Kang et $\mathrm{al}^{23}$ in a 1-year follow-up study investigated three different materials applied to pulpotomy technique. The procedure was classified as safe and predictable with ProRoot MTA, Ortho MTA, or RetroMTA documented through clinical and radiographical data. Bakhtiar et $\mathrm{a}^{24}$ published an in 


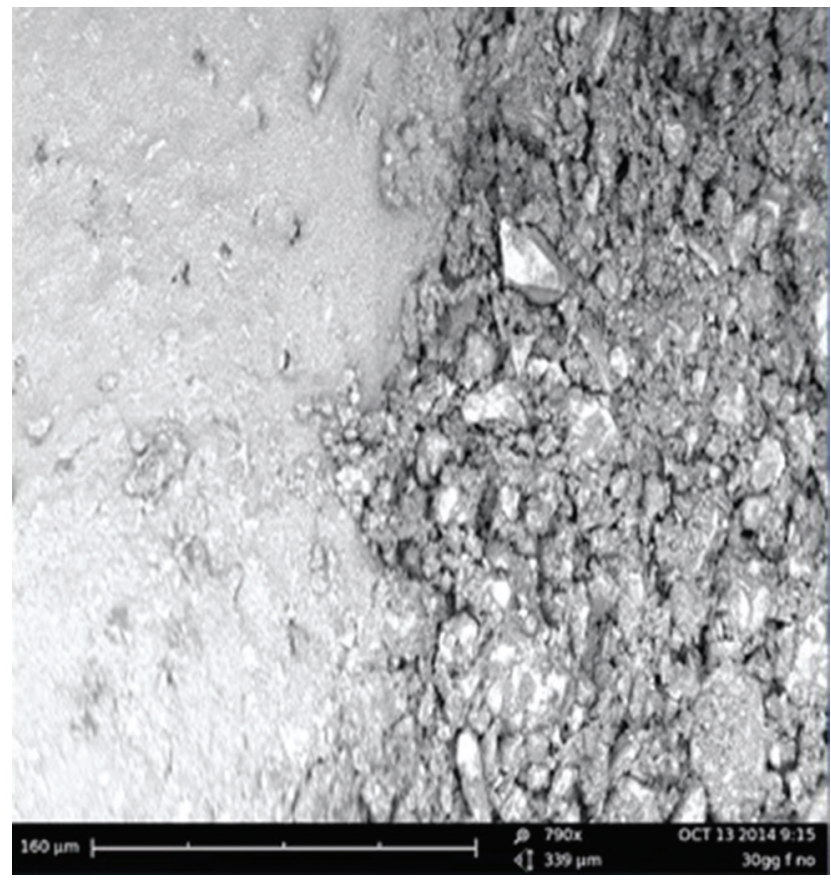

Fig. 3 SEM microleakage between MTA and bonding agents. The MTA use could, in some cases, make the definitive reconstruction complex due to the physical-chemical properties of itself and difficulty of use with hydrophobic substances. MTA, mineral trioxide aggregate; SEM, scanning electron microscope.

vitro study about how some endodontic biomaterials could be efficient than others for the pulp capping procedures. The authors performed histology to evaluate dentinal bridge formation and organization after teeth extraction (disodontiasis third molar). Data demonstrated how Biodentine and ProRoot MTA work better than TheraCal.

According to Asl Aminabadi et al, ${ }^{25}$ there are no radiographic and clinical differences between MTA and 3Mixtatin, and it could represent a valid alternative in direct pulp capping. Aminabadi et $\mathrm{al}^{26}$ evaluated at 24 months the efficiency of 3Mixtatin, showing how this biomaterial could have better clinical result than MTA from a clinical and radiographic point of view. According to the authors, it could represent the future pulp capping material.

Several published articles underlined the clinical features of the MTA just evaluating clinical and radiological data. Nowicka et $\mathrm{al}^{27}$ demonstrated how the reparative dentin bridges are dependent on the material used. Biodentine and MTA resulted in the highest volumes after the cone beam radiography. According to Kang et al, ${ }^{28}$ RetroMTA, Ortho MTA, and ProRoot MTA success rates did not differ and are indistinguishable, and these results indicate that pulpotomy could be performed with a high success rate with all the evaluated biomaterials. Bonte et $\mathrm{al}^{29}$ showed how there is no statistical difference between $\mathrm{Ca}(\mathrm{OH})_{2}$ and MTA, but MTA produced a better dentin healing, apexification using MTA could give better results than $\mathrm{Ca}(\mathrm{OH})_{2}$.

Petrou et $\mathrm{al}^{30}$ concluded that MTA or medical Portland cements are preferable to $\mathrm{Ca}(\mathrm{OH})_{2}$ for indirect pulp capping because those materials are nonresorbable materials. Hilton et $\mathrm{al}^{31}$ showed how MTA is superior for direct pulp capping to $\mathrm{Ca}(\mathrm{OH})_{2}$. Gandolfi et $\mathrm{al}^{32}$ concluded in their study, after a 3D micro-CT analysis, that MTA flow created an apatite layer after 7 days, and AH Plus even after 28 days. Bernabé et al ${ }^{33}$ showed how MTA could be useful item for root canal filling after apicectomy; moreover, a sonic vibration could improve sealing ability. Sönmez et $\mathrm{al}^{34}$ concluded that the sealing ability of AH Plus and ProRoot is similar, but MTA Fillapex showed microleakage compared with the other two materials.

Some studies reported how the results could be modified if the evaluation is reported at 3, 6 months, or 1 year after the treatment. This clinical condition demonstrated how the patient response could be individual and not related to the materials or technique applied. According to Leye Benoist et $\mathrm{al}^{35}$ a higher success rate was observed in the MTA group instead of $\mathrm{Ca}(\mathrm{OH})_{2}$. Differences were significant at 3 months but not at 6 months, with no dentine thickness differences, showing time of evaluation importance. Ghoddusi et $\mathrm{al}^{36}$ concluded that there are no statistical differences between ZOE or MTA treatments, but MTA was successful, expensive, and because of dentin bridges could complicate future root canal therapy. Data reported by Hansen et $\mathrm{al}^{37}$ demonstrated how the MTA produce an intracanal higher $\mathrm{pH}$ than ES. The same result was demonstrated by Yildirim et al. ${ }^{38}$ MTA can be used in the root canals as apical filling materials, in particular, in teeth with postcore indication.

All these results extrapolated by the selected articles provide us documented clinical information and the MTA seems to be as having excellent abilities from the point of view of biocompatibility, as could be seen from the studies, but also of stability over time..$^{39-41}$ The nanocharacteristic of the MTA could be related about its interactions with the human tissue during the endodontic treatment. Remineralizing potential intercepting early lesion progression as nanosized calcium phosphate, carbonate hydroxyapatite nanocrystals, nanoamorphous calcium phosphate, and nanoparticulate bioactive glass particularly with provision of self-assembles protein that furnish essential role in biomimetic repair even in the dental field. The unique size of nanomaterials makes them fascinating carriers for dental products. ${ }^{42-50}$ Thus, it is recently claimed that fortifying the adhesives with nanomaterials that possess biological merits does not only enhance the mechanical and physical properties of the adhesives but also help attain and maintain a durable adhesive joint and enhanced longevity. It is also necessary to report how these conservative therapies often do not expose patients to invasive surgical or not risks, practices that in patients with unfavorable systemic conditions would be complex to apply. Accordingly, this review will focus on the current status and the future implications of nanotechnology in preventive and adhesive dentistry. In dental materials, the main applications of nanotechnology have been to achieve better mechanical properties, higher abrasion resistance, less shrinkage, improved optical, and esthetic properties, and to provide antimicrobial properties. Antimicrobial activity is an important property for nanomaterials used in dentistry because of the lack of this property in resin-based materials. MTA is a biomaterial that has numerous 
possibilities for endodontic therapy, as animal studies and clinical results are highly encouraging. It can also be used in deciduous dentition, with deep carious lesion or exposure to the traumatic pulp intended for endodontic therapy. ${ }^{51-61}$ The MTA could not be used to save all teeth with pulp involvement; however, with a meticulous technique, it could serve as a pulp drug in advance to add to a clinical use. Modern nanotechnology is used in the production of a variety of dental materials such as light-cured composite resins, adhesive systems, impression materials, ceramics, dental implant coatings, and bioceramics, among others. In pediatric age, a whole series of dental malocclusions could occur. There could be different types of dental malocclusions: some are genetic, and others are caused by external factors; the big difference in the treatment of these malocclusions in pediatric and in adulthood is that in children, treatment tends to be much less invasive as the bones have yet to fully develop and it is easier to intervene to correct their shape. Therefore, it should be understood how the absence of a dental element, extracted rather than saved, thanks to an endodontic treatment, even in borderline conditions, thanks to the use of these cements, could have repercussions on the whole stomatognathic system. ${ }^{62,63}$ Moreover, the material is versatile, guaranteeing different uses, and having excellent characteristics in being in contact with the materials for reconstruction. ${ }^{64-77}$

\section{Conclusion}

The results of this review would be certainly useful to fully understand the characteristics and advantages of this biomaterial from a clinical point of view; our structural analysis of the material explains its clinical behavior; and the studies examined are the proof. The numerous clinical, histological, and radiographic tests make this material a safe and predictable material in the endodontic and conservative dentistry fields. Some studies have shown better characteristics than the MTA, above all, from an antibiotic point of view. This could act as a starting point for the improvement of this material and the creation of even better materials.

\section{Authors' Contributions}

Conceptualization, methodology, validation, formal analysis, investigation, resources, data curation, original draft preparation, and review and editing of the manuscript were done by G.C., M.D.T., and L.F.; visualization was performed by D.R., L.N., and C.D.A.; data were curated by G.A., M.T., F.G., and A.T.; L.L. supervised the entire work and L.F. performed project administration.

\section{Funding}

None.

\section{Conflict of Interest}

None declared.

\section{References}

1 Tu MG, Sun KT, Wang TH, et al. Effects of mineral trioxide aggregate and bioceramics on macrophage differentiation and polarization in vitro. J Formos Med Assoc 2019;118(10):1458-1465
2 Serin Kalay T. Effects of intracoronal bleaching agents on the surface properties of mineral trioxide aggregate. Odontology 2019;107(4):465-472

3 Lopes MB, Soares VCG, Fagundes FHR, et al. Analysis of molecular changes induced by mineral trioxide aggregate on SPLA2. Braz Dent J 2019;30(5):453-458

4 Liu Y, Liu XM, Bi J, et al. Cell migration and osteo/odontogenesis stimulation of iRoot FS as a potential apical barrier material in apexification. Int Endod J 2020;53(4):467-477

5 Lin YT, Lin YJ. Success rates of mineral trioxide aggregate, ferric sulfate, and sodium hypochlorite pulpotomies: a prospective 24-month study. J Formos Med Assoc 2019

6 Lapinska B, Klimek L, Sokolowski J, Lukomska-Szymanska M. Dentine surface morphology after chlorhexidine application-SEM study. Polymers (Basel) 2018;10(8):905

7 Cervino G, Fiorillo L, Spagnuolo G, et al. Interface between MTA and dental bonding agents: scanning electron microscope evaluation. J Int Soc Prev Community Dent 2017;7(1):64-68

8 Lo Giudice G, Cutroneo G, Centofanti A, et al. Dentin morphology of root canal surface: a quantitative evaluation based on a scanning electronic microscopy study. BioMed Res Int 2015;2015:164065

9 Zarra T, Lambrianidis T, Vasiliadis L, Gogos C. Effect of curing conditions on physical and chemical properties of MTA. Int Endod J 2018;51(11):1279-1291

10 Colombo M, Poggio C, Dagna A, et al. Biological and physico-chemical properties of new root canal sealers. J Clin Exp Dent 2018;10(2):e120-e126

11 Lo Giudice G, Cicciù M, Cervino G, Lizio A, Visco AM. Flowable resin and marginal gap on tooth third medial cavity involving enamel and radicular cementum: a SEM evaluation of two restoration techniques. Indian J Dent Res 2012;23(6):763-769

12 Fiorillo L, Cervino G, Herford AS, et al. Interferon crevicular fluid profile and correlation with periodontal disease and wound healing: a systemic review of recent data. Int J Mol Sci 2018;19(7):E1908

13 De Stefano R. Psychological factors in dental patient care: odontophobia. Medicina (Kaunas) 2019;55(10):678

14 Cicciù M, Fiorillo L, Cervino G. Chitosan use in dentistry: a systematic review of recent clinical studies. Mar Drugs 2019;17(7):417

15 Savovic J, Turner RM, Mawdsley D, et al. Association between risk-of-bias assessments and results of randomized trials in Cochrane reviews: the ROBES meta-epidemiologic study. Am J Epidemiol 2018;187(5):1113-1122

16 Mansournia MA, Higgins JP, Sterne JA, Hernán MA. Biases in randomized trials: a conversation between trialists and epidemiologists. Epidemiology 2017;28(1):54-59

17 Higgins JP, Altman DG, Gøtzsche PC, et al; Cochrane Bias Methods GroupCochrane Statistical Methods Group. The Cochrane collaboration's tool for assessing risk of bias in randomised trials. BMJ 2011;343:d5928

18 Coburn KM, Vevea JL. Publication bias as a function of study characteristics. Psychol Methods 2015;20(3):310-330

19 Bachelet VC, Pardo-Hernandez H. Quality of reporting and risk of bias of randomized clinical trials published in Spanish and Latin American journals. Medwave 2019;19(1):e7573

20 Çelik BN, Mutluay MS, Arıkan V, Sarı Ş. The evaluation of MTA and Biodentine as a pulpotomy materials for carious exposures in primary teeth. Clin Oral Investig 2019;23(2):661-666

21 Erfanparast L, Iranparvar P, Vafaei A. Direct pulp capping in primary molars using a resin-modified Portland cementbased material (TheraCal) compared to MTA with 12-month follow-up: a randomised clinical trial. Eur Arch Paediatr Dent 2018;19(3):197-203

22 Koc Vural U, Kiremitci A, Gokalp S. Randomized clinical trial to evaluate MTA indirect pulp capping in deep caries lesions after 24-months. Oper Dent 2017;42(5):470-477 
23 Kang CM, Sun Y, Song JS, et al. A randomized controlled trial of various MTA materials for partial pulpotomy in permanent teeth. J Dent 2017;60:8-13

24 Bakhtiar H, Nekoofar MH, Aminishakib P, et al. Human pulp responses to partial pulpotomy treatment with TheraCal as compared with Biodentine and ProRoot MTA: a clinical trial. J Endod 2017;43(11):1786-1791

25 Asl Aminabadi N, Satrab S, Najafpour E, Samiei M, Jamali Z, Shirazi S. A randomized trial of direct pulp capping in primary molars using MTA compared to 3Mixtatin: a novel pulp capping biomaterial. Int J Paediatr Dent 2016;26(4):281-290

26 Aminabadi NA, Huang B, Samiei M, Agheli S, Jamali Z, Shirazi S. A randomized trial using 3Mixtatin compared to MTA in primary molars with inflammatory root resorption: a novel endodontic biomaterial. J Clin Pediatr Dent 2016;40(2):95-102

27 Nowicka A, Wilk G, Lipski M, Kołecki J, Buczkowska-Radlińska J. Tomographic evaluation of reparative dentin formation after direct pulp capping with $\mathrm{Ca}(\mathrm{OH}) 2$, MTA, Biodentine, and dentin bonding system in human teeth. J Endod 2015;41(8):1234-1240

28 Kang CM, Kim SH, Shin Y, et al. A randomized controlled trial of ProRoot MTA, Ortho MTA and RetroMTA for pulpotomy in primary molars. Oral Dis 2015;21(6):785-791

29 Bonte E, Beslot A, Boukpessi T, Lasfargues JJ. MTA versus $\mathrm{Ca}(\mathrm{OH}) 2$ in apexification of non-vital immature permanent teeth: a randomized clinical trial comparison. Clin Oral Investig 2015;19(6):1381-1388

30 Petrou MA, Alhamoui FA, Welk A. Altarabulsi MB, Alkilzy M, $\mathrm{H}$ Splieth C. A randomized clinical trial on the use of medical Portland cement, MTA and calcium hydroxide in indirect pulp treatment. Clin Oral Investig 2014;18(5):1383-1389

31 Hilton TJ, Ferracane JL, Mancl L; Northwest Practice-based Research Collaborative in Evidence-based Dentistry (NWP). Comparison of $\mathrm{CaOH}$ with MTA for direct pulp capping: a PBRN randomized clinical trial.J Dent Res 2013;92(7(Suppl):16S-22S

32 Gandolfi MG, Parrilli AP, Fini M, Prati C, Dummer PM. 3D micro-CT analysis of the interface voids associated with Thermafil root fillings used with AH Plus or a flowable MTA sealer. Int Endod J 2013;46(3):253-263

33 Bernabé PF, Gomes-Filho JE, Bernabé DG, et al. Sealing ability of MTA used as a root end filling material: effect of the sonic and ultrasonic condensation. Braz Dent J 2013;24(2):107-110

34 Sönmez IS, Oba AA, Sönmez D, Almaz ME. In vitro evaluation of apical microleakage of a new MTA-based sealer. Eur Arch Paediatr Dent 2012;13(5):252-255

35 Leye Benoist F, Gaye Ndiaye F, Kane AW, Benoist HM, Farge P. Evaluation of mineral trioxide aggregate (MTA) versus calcium hydroxide cement (Dycal( $\left({ }^{\circledR}\right)$ ) in the formation of a dentine bridge: a randomised controlled trial. Int Dent J 2012;62(1):33-39

36 Ghoddusi J, Shahrami F, Alizadeh M, Kianoush K, Forghani M. Clinical and radiographic evaluation of vital pulp therapy in open apex teeth with MTA and ZOE. N Y State Dent J 2012;78(3):34-38

37 Hansen SW, Marshall JG, Sedgley CM. Comparison of intracanal EndoSequence root repair material and ProRoot MTA to induce $\mathrm{pH}$ changes in simulated root resorption defects over 4 weeks in matched pairs of human teeth. J Endod 2011;37(4):502-506

38 Yildirim T, Taşdemir T, Orucoglu H. The evaluation of the influence of using MTA in teeth with post indication on the apical sealing ability. Oral Surg Oral Med Oral Pathol Oral Radiol Endod 2009;108(3):471-474

39 Jinga SI, Voicu G, Stoica-Guzun A. Stroescu M, Grumezescu AM, Bleotu C. Biocellulose nanowhiskers cement composites for endodontic use. Dig J Nanomater Biostructures 2014;9(2):543-550

40 Voicu G, Bădănoiu AI, Ghițulică CD, Andronescu E. Solgel synthesis of white mineral trioxide aggregate with potential use as biocement. Dig J Nanomater Biostructures 2012;7(4):1639-1646

41 Tao O, Wu DT, Pham HM, Pandey N, Tran SD. Nanomaterials in craniofacial tissue regeneration: a review. Appl Sci 2019;9(2):317

42 Jun SK, Yoon JY, Mahapatra C, et al. Ceria-incorporated MTA for accelerating odontoblastic differentiation via ROS downregulation. Dent Mater 2019;35(9):1291-1299

43 Opačić-Galić V, Petrović V, Jokanović V, Živković S. Histological evaluation of tissue reactions to newly synthetized calcium silicate-and hydroxyapatite-based bioactive materials - in vivo study. Srp Arh Celok Lek 2017;145(0):63-63

44 Huq NL, Myroforidis H, Cross KJ, et al. The interactions of CPPACP with saliva. Int J Mol Sci 2016;17(6):E915

45 Heller D, Helmerhorst EJ, Oppenheim FG. Saliva and serum protein exchange at the tooth enamel surface. J Dent Res 2017;96(4):437-443

46 Gibbins HL, Yakubov GE, Proctor GB, Wilson S, Carpenter GH. What interactions drive the salivary mucosal pellicle formation? Colloids Surf B Biointerfaces 2014;120:184-192

47 Culp DJ, Robinson B, Parkkila S, et al. Oral colonization by Streptococcus mutans and caries development is reduced upon deletion of carbonic anhydrase VI expression in saliva. Biochim Biophys Acta 2011;1812(12):1567-1576

48 Hannig M, Hannig C. Nanomaterials in preventive dentistry. Nat Nanotechnol 2010;5(8):565-569

49 Khurshid Z, Zafar M, Qasim S, Shahab S, Naseem M, AbuReqaiba A. Advances in nanotechnology for restorative dentistry. Materials (Basel) 2015;8(2):717-731

50 Kanaparthy R, Kanaparthy A. The changing face of dentistry: nanotechnology. Int J Nanomedicine 2011;6:2799-2804

51 Subramani K, Ahmed W, Hartsfield JK, Nanobiomaterials in Clinical Dentistry; 2012

52 Cicciù $M$, Cervino $G$, Terranova $A$, et al. Prosthetic and mechanical parameters of the facial bone under the load of different dental implant shapes: a parametric study. Prosthesis 2020;1:41-53

53 Cicciù M. Prosthesis: new technological opportunities and innovative biomedical devices. Prosthesis 2020;1:1-2

54 Crimi S, Fiorillo L, Bianchi A, et al. Herpes virus, oral clinical signs and QoL: systematic review of recent data. Viruses 2019;11(5):463

55 Zhang N, Zhang K, Xie X, et al. Nanostructured polymeric materials with protein-repellent and anti-caries properties for dental applications. Nanomaterials (Basel) 2018;8(6):393

56 Guazzo R, Gardin C, Bellin G, et al. Graphene-based nanomaterials for tissue engineering in the dental field. Nanomaterials (Basel) 2018;8(5):349

57 Troiano G, Laino L, Cicciù M, et al. Comparison of two routes of administration of dexamethasone to reduce the postoperative sequelae after third molar surgery: a systematic review and meta-analysis. Open Dent J 2018;12:181-188

58 Laino L, Cicciù M, Fiorillo L, et al. Surgical risk on patients with coagulopathies: guidelines on hemophiliac patients for oro-maxillofacial surgery. Int J Environ Res Public Health 2019;16(8):1386

59 Fiorillo L, De Stefano R, Cervino G, et al. Oral and psychological alterations in haemophiliac patients. Biomedicines 2019;7(2):33

60 Cervino G, Fiorillo L, Monte IP, et al. Advances in antiplatelet therapy for dentofacial surgery patients: focus on past and present strategies. Materials (Basel) 2019;12(9):1524

61 Herford AS, Lu M, Akin L, Cicciù M. Evaluation of a porcine matrix with and without platelet-derived growth factor for bone graft coverage in pigs. Int J Oral Maxillofac Implants 2012;27(6):1351-1358

62 Sambataro S, Cervino G, Bocchieri S, La Bruna R, Cicciù M. TMJ dysfunctions systemic implications and postural assessments: 
a review of recent literature. J Funct Morphol Kinesiol 2019;4:58

63 Sambataro S, Bocchieri S, Cervino G, et al. Correlations between malocclusion and postural anomalies in children with mixed dentition. J Funct Morphol Kinesiol 2019;4:45

64 Cicciù M, Risitano G, Lo Giudice G, Bramanti E. Periodontal health and caries prevalence evaluation in patients affected by Parkinson's disease. Parkinsons Dis 2012;2012:541908

65 Cicciù M, Bramanti E, Cecchetti F, Scappaticci L, Guglielmino E, Risitano G. FEM and Von Mises analyses of different dental implant shapes for masticatory loading distribution. Oral Implantol (Rome) 2014;7(1):1-10

66 Cicciù M, Beretta M, Risitano G, Maiorana C. Cemented-retained vs screw-retained implant restorations: an investigation on 1939 dental implants. Minerva Stomatol 2008;57(4):167-179

67 Algarni AA, Mussi MC, Moffa EB, et al. The impact of stannous, fluoride ions and its combination on enamel pellicle proteome and dental erosion prevention. PLoS One 2015;10(6):e0128196

68 Rodríguez-Lozano FJ, López-García S, García-Bernal D, et al. In vitro effect of putty calcium silicate materials on human periodontal ligament stem cells. Appl Sci 2020;10(1):325

69 Tatullo M, Spagnuolo G, Codispoti B, et al. PLA-based mineral-doped scaffolds seeded with human periapical cyst-derived MSCs: a promising tool for regenerative healing in dentistry. Materials (Basel) 2019;12(4):E597

70 Spagnuolo G, Codispoti B, Marrelli M, Rengo C, Rengo S, Tatullo M. Commitment of oral-derived stem cells in dental and maxillofacial applications. Dent J (Basel) 2018;6(4):E72
71 de Oliveira NG, de Souza Araújo PR, da Silveira MT, Sobral APV, Carvalho MV. Comparison of the biocompatibility of calcium silicate-based materials to mineral trioxide aggregate: systematic review. Eur J Dent 2018;12(2):317-326

72 Ferreira MM, Botelho MF, Abrantes M, Carvalho L, Carrilho E. Histologic evaluation of the effect of mineral trioxide aggregate-Fillapex as a root canal sealer in rat teeth submitted to late replantation. Eur J Dent 2017;11(1):89-93

73 Scrascia R, Fiorillo L, Gaita V, Secondo L, Nicita F, Cervino G. Implant-supported prosthesis for edentulous patient rehabilitation. From temporary prosthesis to definitive with a new protocol: a single case report. Prosthesis 2020;2(1):10-24

74 Ortensi L, Vitali T, Bonfiglioli R, Grande F. New tricks in the preparation design for prosthetic ceramic laminate veeners. Prosthesis 2019;1(1):29-40

75 Lee DS, Lim MJ, Choi Y, Rosa V, Hong CU, Min KS. Tooth discoloration induced by a novel mineral trioxide aggregate-based root canal sealer. Eur J Dent 2016;10(3):403-407

76 Bayram E, Bayram HM. Fracture resistance of immature teeth filled with mineral trioxide aggregate, bioaggregate, and Biodentine. Eur J Dent 2016;10(2):220-224

77 Akcay H, Arslan H, Akcay M, Mese M, Sahin NN. Evaluation of the bond strength of root-end placed mineral trioxide aggregate and Biodentine in the absence/presence of blood contamination. Eur J Dent 2016;10(3):370-375 